\title{
Systematic review of stereotactic body radiotherapy in stage III non-small cell lung cancer
}

\author{
Olwen Leaman Alcibar ${ }^{1}$, Ernest Nadal ${ }^{2,3}$, Inmaculada Romero Palomar $^{4}$, Arturo Navarro-Martin ${ }^{5}$ \\ ${ }^{1}$ Department of Radiation Oncology, Gregorio Marañón General University Hospital, Madrid, Spain; ${ }^{2}$ Department of Medical Oncology, \\ Catalan Institute of Oncology, L'Hospitalet, Barcelona, Spain; ${ }^{3}$ Clinical Research in Solid Tumors (CReST) group, Oncobell Program, Bellvitge \\ Biomedical Research Institute (IDIBELL), L'Hospitalet, Barcelona, Spain; ${ }^{4}$ Gregorio Marañón General University Hospital Library, Madrid, Spain; \\ ${ }^{5}$ Department of Radiation Oncology, Catalan Institute of Oncology, L'Hospitalet, Barcelona, Spain \\ Contributions: (I) Conception and design: All authors; (II) Administrative support: All authors; (III) Provision of study materials or patients: A \\ Navarro-Martin, OL Alcibar, I Romero Palomar; (IV) Collection and assembly of data: OL Alcibar, A Navarro-Martin; (V) Data analysis and \\ interpretation: OL Alcibar, A Navarro-Martin, E Nadal; (VI) Manuscript writing: All authors; (VII) Final approval of manuscript: All authors. \\ Correspondence to: Dr. Arturo Navarro-Martin, MD, PhD. Department of Radiation Oncology, Catalan Institute of Oncology, Avda. Gran Via 199- \\ 203. L'Hospitalet, Barcelona, Spain. Email: anavarro@iconcologia.net.
}

\begin{abstract}
Despite adequate treatment, 50\% of stage III locally advanced inoperable non-small cell lung cancer (NSCLC) patients have a locoregional relapse. Local control on early stages on the contrary, is as high as $85-90 \%$ with stereotactic body radiotherapy (SBRT). The addition of SBRT to conventional chemoradiation or its use in monotherapy in stage III NSCLC is a novel strategy to decrease local failure that has been explored by various authors. This is a systematic review of studies using SBRT in inoperable stage III NSCLC. Search results obtained 141 articles of which only 6 original studies were pointed as relevant. Three of these studies were prospective, of which 2 were phase I dose-scalation studies and remaining 3 were retrospective. In summary, SBRT outcomes on 134 patients were included. Median dose in the SBRT treatment was 22.5 Gy in 2 to 7 fractions. Obtained global toxicity was $3.7 \%$ grade 5 and $14.17 \%$ grade 3. Dose-escalation studies proposed a 2 fraction SBRT schedule of 20-24 Gy, obtaining a 78\% local control rate at 1 year and an OS of $67 \%$. Initial improvement in local control with this innovative therapeutic strategy has led to ongoing phase II and III clinical trials that will evaluate the efficiency of SBRT in stage III NSCLC clinical scenario.
\end{abstract}

Keywords: Stereotactic body radiotherapy (SBRT); stereotactic ablative radiotherapy (SABR); locally advance non-small cell lung cancer (NSCLC); stage III

Submitted Mar 15, 2020. Accepted for publication May 18, 2020.

doi: $10.21037 /$ tlcr-2020-nsclc-04

View this article at: http://dx.doi.org/10.21037/tlcr-2020-nsclc-04

\section{Introduction}

Stage III unresectable non-small cell lung cancer (NSCLC) represents approximately $20 \%$ (1) of all patients diagnosed with NSCLC. For years, the standard treatment has been thoracic radiotherapy 60-66 Gy in 30-33 daily fractions with concomitant cisplatin based chemotherapy (2), offering an overall survival rate at 5 years between $15-25 \%$ (3). Nowadays, consolidation with Durvalumab represents the new standard of care in patients with $\mathrm{PD}-\mathrm{L} 1 \geq 1 \%$ and no progression after chemoradiation (4). However, intrathoracic progression in the Durvalumab arm showed just a little difference with the placebo arm, 36.6\% vs. $48.1 \%$. Therefore in stage III clinical scenario, local relapse continues being a mayor challenge.

Specifically, local relapse in stage III NSCLC can vary from $20 \%$ to $50 \%$ (5). Dose escalation with conventional radiotherapy to the lung tumor is related to higher local control but also to a higher toxicity. In that sense, the RTOG 0617 (6) study was a game-changer, as it 
demonstrated how, higher doses to organs at risk like the heart, were fundamental to explain the toxicity seen at dose escalation studies.

On the other hand, stereotactic body radiotherapy (SBRT) encompasses a technique that can deliver high dose conformal radiation through multiple radiation beams with steep dose gradients in 3-8 fractions. In early stage NSCLC, SBRT studies have demonstrated local control rates as far as $94 \% 3$ years post-treatment $(7,8)$. Nevertheless, in very central lesions or tumors with mediastinal lymph node infiltration, grade 3 or higher toxicity can reach $46 \%$ (9).

Consequently, using dose escalation with SBRT technique to improve local control in stage III NSCLC seems an attractive strategy. Scientific literature available on the topic as far as dose to deliver, toxicity profile and possible concomitant treatments to combine is scarce. This systematic review summarizes the current scientific evidence on the use of SBRT in locally advanced inoperable NSCLC (stage III).

\section{Material and methods}

A systematic review on the literature was performed using PubMed-Medline, Embase and Scopus databases. Relevant articles on SBRT usage in inoperable stage III NSCLC were identified using the following terms in the Medical Subject Heading (MeSH):

(SBRT or SABR or stereotactic [MeSH Terms]) AND (NSCLC or Carcinoma or Non small cell lung or Nonsmall-cell Lung or Lung carcinoma or Non-small-cell Lung Carcinoma or Nonsmall Cell lung Carcinoma or Nonsmall Cell Lung Cancer or Non-Small-Cell Lung Carcinoma or Non Small Cell Lung Carcinoma or Non-Small Cell Lung Cancer [MeSH Terms]) AND (Stage III [MeSH Terms].

Search syntax was adapted to Embase and Scopus databases in order to find relevant articles on the topic. We included studies up to December 2019.

The articles found on the systematic review were independently examined by two investigators (OLA and ANM). Interesting articles related to the topic that were found outside the initial systematic review were included. Discrepancies between the reviewers were analyzed together and a consensus was reached.

Included studies for the review were those that administered SBRT as a boost after or before conventional chemoradiotherapy, those that administered SBRT in monotherapy and reviews on the administration of SBRT in inoperable stage III NSCLC. Studies that did not report administered doses or that did not include outcomes such as toxicity, progression free survival or local control were excluded. Articles that were not published in English or did not have the complete text available were also excluded.

This systematic review has been carried out following the Preferred Reporting Items for Systematic Reviews and Meta-Analyses (PRISMA) guidelines (Figure 1). To measure quality of the studies the NIH quality-measure tool for this purpose was used available at https://www.nhlbi.nih.gov/ health-topics/study-quality-assessment-tools.

\section{Results}

Systematic review on the three databases above mentioned extracted 141 studies, 11 of which met inclusion criteria $(5,10-19)$ (Figure 1). Two studies were reviews $(5,15)$, one did not include clinical data (17), two studies had preliminary results $(11,12), 3$ were prospective studies and another 3 were retrospective. For quantitative and qualitative analysis 6 articles were fully reviewed (Table 1).

In the studies that met the inclusion criteria, a total of 134 patients affected of stage III inoperable NSCLC were treated with SBRT some time during the therapeutic strategy. These studies were carried out between 2008 and 2019 in different centers, majority of them in United States, and one in China. In relation to the design of the studies included, 3 studies had a prospective design, 2 of which were phase I. The remaining 3 were retrospective series. Sample size for each study and results are described in Table 1.

Out of the 6 original studies that considered SBRT administration in stage III NSCLC, 1 employed SBRT in monotherapy (10) and the other 5 employed SBRT as a dose escalation technique in the context of conventional chemoradiotherapy $(13,14,16,18,19)$.

Studies that administered SBRT as a dose intensification technique had a median dose in the conventional radiotherapy of $50.4 \mathrm{~Gy}$ in a median of 28 fractions. Additionally, the median dose in the SBRT boost was 22.25 Gy delivered in 2 to 7 fractions.

Systemic treatment employed for conventional chemoradiotherapy was platinum-based. One of the studies included FDG PET-CT scan as a tool for contouring the gross tumor volume (GTV) for the boost. The rest of the studies relied on CT scans to delineate the GTV. Three studies included the primary tumor and the affected lymph nodes in the SBRT therapeutic volume. The remaining two, on the contrary, included the primary tumor but not the lymph nodes. Reported 

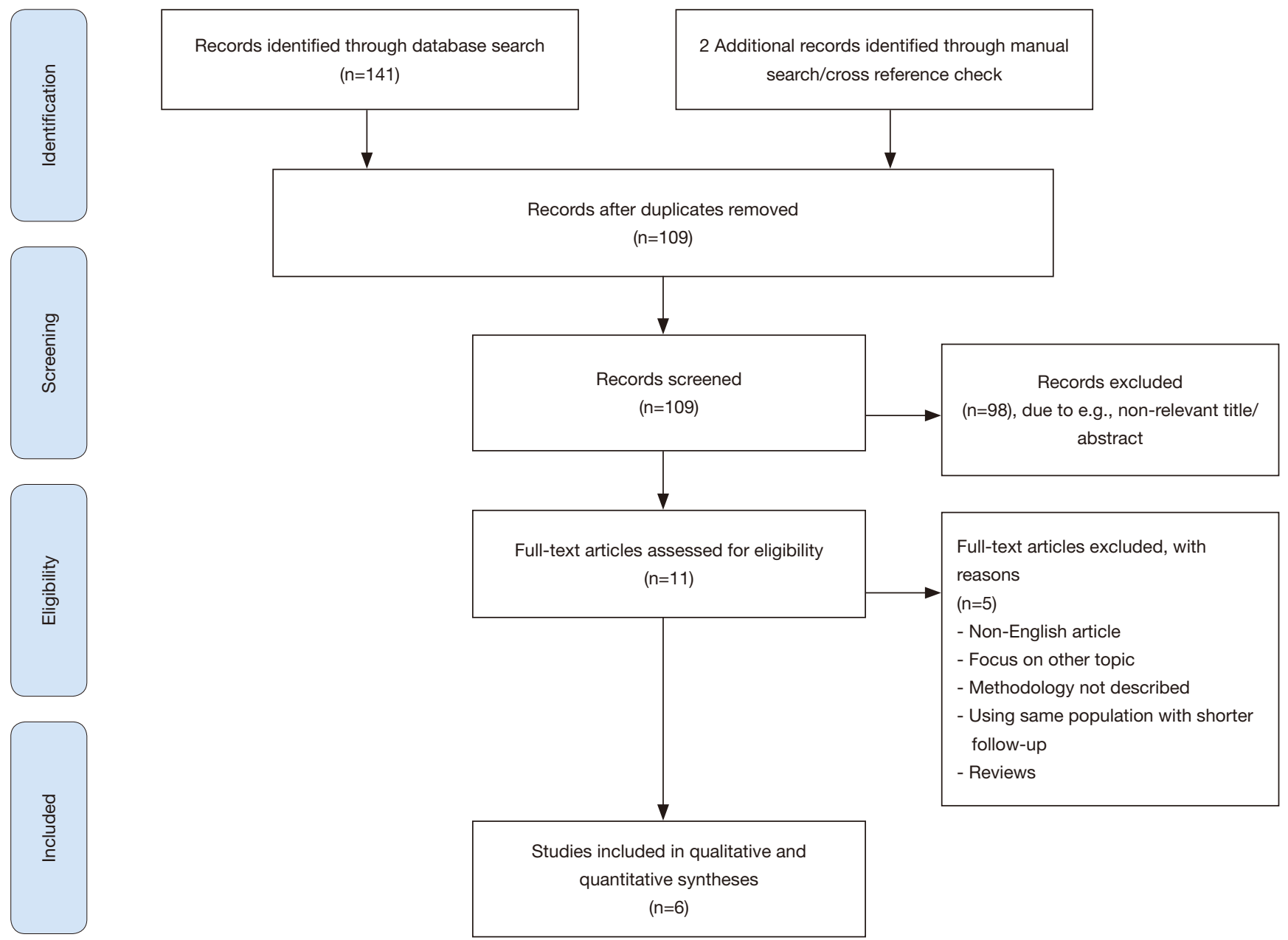

Figure 1 PRISMA flow diagram.

median follow-up was 18.75 months. Median local control was $76 \%$. As far as toxicity is concerned, $12 \%$ of patients experienced grade 3 or higher toxicity.

The phase I dose-escalation study by Hepel et al. included 12 patients (13). Primary objective was to obtain dose limiting toxicity (DLT) for toxicity such as pneumonitis, oesophageal fistula, cardiac toxicity, bone fractures or dermatitis. Four dose schedules are described, from 16 to 28 Gy administered in 2 fractions and incrementing dose per fraction by $4 \mathrm{~Gy}$ in each cohort. Following its primary objective (DLT), 3 patients per cohort-dose were included using a classical $3 \times 3$ trial design.

Patients on Hepel's study underwent chemoradiotherapy previously at a dose of $50.4 \mathrm{~Gy}$ in 28 fractions. Most common systemic treatment to combine with radiation was 2 cycles of cisplatin and etoposide every 3 weeks or carboplatin-taxol weekly for 6 weeks. After conventional chemoradiotherapy, a CT scan was obtained to address the remaining tumor in order to plan SBRT treatment that would be administered 1 to 4 weeks after.

In this case, both the remaining primary tumor and lymph nodes were included in the treatment field. Four dose cohorts were reached, where grade 3 or superior toxicity was not observed. $42 \%$ of the patients received consolidation chemotherapy for 2 more cycles.

With a median follow-up of 15.5 months, local control the first year was $78 \%$ and $100 \%$ in 6 patients who received 24 Gy or higher doses. Overall survival of the whole study was $67 \%$. One patient on the 24 Gy cohort experienced grade 5 toxicity in peribronchial vasculature.

The other phase I dose-escalation study published in 2017 by Higgins et al. (14) included 19 patients and its primary 


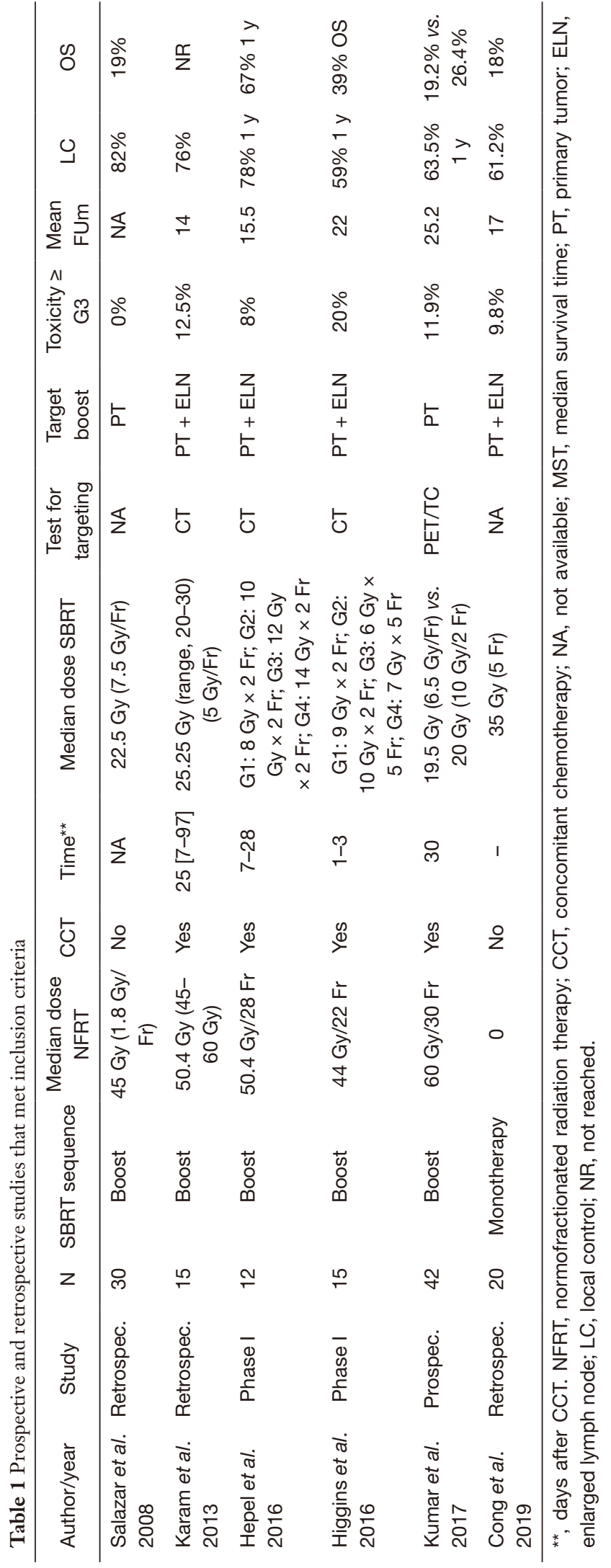

objective was also to determine the maximal tolerated dose (MTD). Four dose cohorts were designed: 18 Gy (9 Gy $\times 2 \mathrm{Fr}), 20 \mathrm{~Gy}(10 \mathrm{~Gy} \times 2 \mathrm{Fr}), 30 \mathrm{~Gy}(6 \mathrm{~Gy} \times 5 \mathrm{Fr})$ and 35 Gy $(7 \mathrm{~Gy} \times 5 \mathrm{Fr})$. In a similar manner, 3 patients per dose-cohort were included. They all underwent conventional chemoradiotherapy previously at a dose of 44 Gy in 2 Gy fractions concurrent to weekly carboplatin $\left(45-50 \mathrm{mg} / \mathrm{m}^{2}\right)$ and paclitaxel (AUC 2).

Consolidation chemotherapy was at the discretion of the clinician and $73 \%$ received it. The third dose cohort (6 Gy $\times 5 \mathrm{Fr}$ ) had a grade 5 tracheo-esophageal fistula that derived in death of the patient. Another 2 patients at the fourth dose cohort (7 Gy $\times 5 \mathrm{Fr}$ ) presented grade 3 or higher toxicity: one grade 5 hemoptysis and one grade 3 hypoxia. With these findings, authors conclude that the save dose range would be 20 Gy in 2 fractions.

Residual disease in this case was measured with CT scans and SBRT was delivered to the primary tumor and the remaining lymph nodes. Local control rate was $59 \%$ the first year and overall survival was $39 \%$.

The third and last prospective study was published in 2017 by Kumar et al. (16). Patients with inoperable stage IIB (4p) and IIIA-B (38p) were included. Median follow-up was 25 months. Primary objective of the study was to determine the safety or toxicity profile of an SBRT boost. All patients received conventional chemoradiotherapy (59.4-60 Gy with standard 180-200 cGy fractions). In this case, PET-CT was achieved 1 month after termination of chemoradiotherapy, and the remaining disease was included in the SBRT boost. 2 dose cohort were designed: $10 \mathrm{~Gy} \times 2$ fractions for tumors in the periphery (28p) and $6.5 \mathrm{~Gy} \times 3$ fractions for central tumors (14p). Boost did not include lymph nodes. The median time between chemoradiotherapy and SBRT delivery was 2.9 months. One-year local control of the study was $63.6 \%$. Toxicity rate was $11.9 \%$ grade 3 with no grade 4 or higher toxicity.

Out of the three retrospective studies that met the selection criteria, the study by Cong stands out due to its innovative therapeutic approach (10). In this case, SBRT is administered in monotherapy for stage III NSCLC with a Cyberknife at a median dose of 35 Gy in 5 fractions. Primary tumor and lymph nodes were both included in the treatment volume. Median follow-up time was 17 months with a local control rate of $61 \%$. Grade 3 toxicity or higher was $9.8 \%$.

As far as the retrospective work of Salazar et al. (18), SBRT was delivered in different NSCLC clinical scenarios, including metastasis. In summary, 30 patients were stage 


\begin{tabular}{|c|c|c|c|}
\hline Questions for Assessment & Hepel et al. & Higgins et al. & Kumar et al. \\
\hline Was the study question or objective clearly stated? & & & \\
\hline $\begin{array}{l}\text { Were eligibility/selection criteria for the study population } \\
\text { prespecified and clearly described? }\end{array}$ & $(\bullet)$ & & \\
\hline $\begin{array}{l}\text { Were the participants in the study representative of those who } \\
\text { would be eligible for the test/service/intervention in the general or } \\
\text { clinical population of interest? }\end{array}$ & & & \\
\hline $\begin{array}{l}\text { Were all eligible participants that met the prespecified entry criteria } \\
\text { enrolled? }\end{array}$ & & & \\
\hline $\begin{array}{l}\text { Was the sample size sufficiently large to provide confidence in the } \\
\text { findings? } \\
\text { Was the test/service/intervention clearly described and delivered } \\
\text { consistently across the study population? }\end{array}$ & & & \\
\hline $\begin{array}{l}\text { Were the outcome measures prespecified, clearly defined, valid, } \\
\text { reliable, and assessed consistently across all study participants? }\end{array}$ & & & \\
\hline $\begin{array}{l}\text { Were the people assessing the outcomes blinded to the } \\
\text { participants' exposures/interventions? }\end{array}$ & & & \\
\hline $\begin{array}{l}\text { Was the loss to follow-up after baseline } 20 \% \text { or less? Were those } \\
\text { lost to follow-up accounted for in the analysis? }\end{array}$ & (ت) & & \\
\hline $\begin{array}{l}\text { Did the statistical methods examine changes in outcome measures } \\
\text { from before to after the intervention? Were statistical tests done } \\
\text { that provided p values for the pre-to-post changes? }\end{array}$ & $(\bullet$ & & \\
\hline $\begin{array}{l}\text { Were outcome measures of interest taken multiple times before the } \\
\text { intervention and multiple times after the intervention (i.e., did they } \\
\text { use an interrupted time-series design)? }\end{array}$ & (ت) & & \\
\hline $\begin{array}{l}\text { If the intervention was conducted at a group level did the statistical } \\
\text { analysis take into account the use of individual-level data to } \\
\text { determine effects at the group level? }\end{array}$ & & & \\
\hline
\end{tabular}

(:) Yes; : No.

Figure 2 Study Quality assessment tool for before-after studies with no control group.

III and were included in this review. They received conventional radiotherapy total dose 45 Gy in 25 fractions and SBRT boost in 3 fractions of 7.5 Gy each to the primary tumor (excluding lymph nodes). Obtained local control by stages was: $73 \%$ in stage IIIA and $47 \%$ in stage IIIB. Information about systemic therapy was not available. No grade 3 or higher toxicity was detected.

Finally, the retrospective study by Karam et al. (19) included 16 patients, all stage III. Conventional chemoradiotherapy was delivered with a median total dose of 50.4 Gy. In order to identify the SBRT volume during treatment, 4 fiducial markers were placed prior to simulation. Median follow-up reached 14 months, with an overall survival at 1 year of $78 \%$. Local and regional control were $76 \%$ and $79 \%$ respectively. Toxicity was not graded accurately, although information on one patient developing hemoptysis and another pneumonitis is given.

The overall quality of the studies was measured using the NIH "Study quality assessment tools". Specifically, "beforeafter studies with no control group" was used to measure the prospective studies, and the "quality case series studies" was used to measure the retrospective studies (see Figures 2,3).

\section{Discussion}

Standard treatment for stage III inoperable NSCLC remains conventional chemoradiotherapy; systemic therapy being platinum-based and radiation doses going up to $60-$ 66 Gy in 2 Gy daily fractions $(4,20)$.

The primary objective of this systematic review was to stablish first clinical experiences and the existing scientific evidence supporting the use of SBRT in inoperable stage III NSLCL as a tool to decrease local failure. Six relevant studies were found. After careful examination, two principal therapeutic strategies were identified: on one hand, the use of SBRT as a boost after conventional chemoradiation, and on the other, the use of SBRT in monotherapy in those patients that are not good candidates for conventional chemoradiation.

Interestingly, SBRT treatment volume design differs from study to study. Sometimes it includes just the primary tumor in order to reduce toxicity, and in other cases, it 


\begin{tabular}{|l|c|c|}
\hline Questions for Assessment & Salazar et al. & Karam et al. \\
\hline Was the study question or objective clearly stated? & $\begin{array}{l}\text { Cong et al. } \\
\text { Was the study population clearly and fully described, }\end{array}$ & \\
\hline Were the cases consecutive? & Were the subjects comparable? & Na case definition?
\end{tabular}

(:) Yes; :) No. NA, not available.

Figure 3 Quality assessment tool for case series studies.

includes positive lymph nodes too instead.

\section{SBRT volume}

Stage III NSCLC disease is characterized by lymph node involvement in the mediastinum. The administration of SBRT in this stage poses an important risk of toxicity due to proximity of critical organs like bronchi, esophagus, large vessels and the heart. Classically, central lung lesions have been defined as those at a distance of $2 \mathrm{~cm}$ or less from the mediastinum or principal bronchi (21). In studies that used SBRT to central lesions in early stages, grade 3 or higher toxicity was reported as $9 \%$ (22). Nevertheless, treatment volumes did not include positive lymph nodes. Up to date, SBRT administration to treat lymph nodes has been anecdotic and doses to administer are therefore not clear (23).

In our systematic review, 5 out of 7 studies used SBRT technique as a dose-intensification method after concurrent chemoradiotherapy. In these studies, initial disease-volume is reduced with conventional treatment in order to pursue a safer SBRT treatment volume. Two studies (Salazar and Kumar et al.) include solely the primary tumor in the intention to treat volume. Grade 3 toxicity reported by these authors is $0 \%$ and $11.9 \%$ respectively. Remaining studies include the involved lymph nodes in the SBRT volume as well as the primary tumor and grade 3 toxicity reported varies from $8 \%$ to $20 \%$.

\section{Imaging technique to determine the GTV}

Choice of imaging technique in the design of the GTV differs from study to study. Residual disease identification after conventional chemoradiotherapy is fundamental to make an impact in locoregional control and most probably, on overall survival. In this regard, just one study (16) included PET-CT at one-month completion of chemoradiotherapy to determine the residual disease.

At present, the standardization of radiomics in PET scans and the study of its prognostic value for lung cancer has been studied (24). Whether PET can be an independent prognosis factor in lung cancer in order to select patients for treatment intensification after chemoradiation is also currently under consideration (25).

\section{Dose election}

In the studies previously mentioned, median dose for SBRT was 22.25 Gy with a number of fractions ranging from 2 to 7 . Two studies are phase I dose-escalation 
studies. Higgins (14) reported an MTD at $6 \mathrm{~Gy} \times 5$ Fr dose after conventional chemoradiation of 44 Gy 2 Gy/fraction. Authors conclude that $20 \mathrm{~Gy}$ in 2 fractions of $10 \mathrm{~Gy}$ is safer.

Nevertheless, in the other phase I study by Hepel (13), local control is higher when dose is equal o higher than 24 Gy in 2 fractions, and in contrast, toxicity is lower (8\% versus $15.78 \%)$. The gain in local control in the Hepel study $(78 \%$ vs. $59 \%$ ) could be related to the biological effective dose administered (BED), which is superior: 126.7 versus $112.3 \mathrm{~Gy}$.

On the other hand, locoregional control is not specified in the different dose cohorts, so concluding which dose per fraction is best for this objective is difficult. In this regard, Kumar et al. (16) concluded that local and regional control are similar in the different schemes evaluated: $10 \mathrm{~Gy} \times 2$ Fr vs. 6.5 Gy $\times 3$ Fr. However, data in this study has given us much thought. To start, local failure in the $6.5 \mathrm{~Gy} \times 3$ cohort and 10 Gy $\times 2$ cohort is $14 \%$ and $21 \%$ respectively. Meanwhile, biological effective dose for each cohort goes as follows: $\mathrm{BED}_{10} 32.2$ versus $40 \mathrm{~Gy}$. In conclusion, the higher BED cohort has a worse local failure, the opposite of what is generally accepted. To our understanding, this may be in relation to the immune changes occurring after repeated doses of radiation, favoring the $6.5 \mathrm{~Gy} \times 3$ cohort as seen in mice studies on the topic (26). In addition, ablative doses per fraction of around $10 \mathrm{~Gy}$, have a deleterious effect on interferon activation genes due to the activation of exonuclease TREX1, who is capable of fragmenting the tumor nucleic acid in the dendritic cell and as a result, inhibit cGAS-STING pathway $(27,28)$.

\section{Consolidation after SBRT}

In the studies selected, there is a lack of information regarding the use of consolidation systemic therapy. Out of the three studies that do inform on the matter, the proportion of patient receiving this treatment varies from $6 \%$ to $73 \%$. In the present, consolidation treatment with immunotherapy is standard of care due to the publication of the PACIFIC TRIAL (29), where durvalumab demonstrated an improved overall survival: $83.1 \%$ at 1 year. If we compare OS of SBRT studies and OS of the PACIFIC trial, it is clear that the second is higher. In terms of intrathoracic disease control, the combination of conventional chemoradiotherapy and immunotherapy manages a $60 \%$ local control. Whether the combination of triple therapy (conventional chemoradiotherapy + SBRT + durvalumab) is safe or effective is yet to be determined in future studies. Nevertheless, the combination of multisite SBRT and pembrolizumab has already been tested and toxicity was much lower than expected (30).

As previously explained, according to research on fractionation and cGAS-STING pathway activation, a systemic immune response with SBRT can be obtained at lower radiation doses, and therefore toxicity to the mediastinum organs could be avoided. In addition, the smaller treatment fields achieved with SBRT technique decrease surrounding lymphopenia compared to conventional radiation and overall make this technique safer and more suitable for immune activation and immune combinations.

\section{Toxicity}

Toxicity observed throughout the studies is diverse and does not follow a linear relation to dose in most cases. Majority of studies applied dose constraints published previously by other authors that administered lung SBRT. In some cases, like the deceased due to hemoptysis in the Hepel study (13), maximum tolerated doses to the proximal bronchial tree were not stablished. As a result, an amendment was made for treatment of future patients stablishing a new dose constraint to this organ at risk. Other authors (16), adapted fractionation in central lesions to be more conservative. None of the studies report acute irreversible toxicity, although distinction between acute and chronic toxicity is not clear. Higgins group (14) considers acute toxicity whatever is detected in the first 30 days post-SBRT delivery and other groups stablish acute toxicity in the first 90 days. In any case, severe toxicity appears late, for which doseescalation studies are not adequate.

In the RTOG 0813 study (31), where SBRT was delivered to central tumors, a time-to-event continual reassessment method (TITE-CRM) (32) design was used that account for this late toxicity. The advantage of this method is it has the ability to calculate MTD without exposing the patient to a higher toxicity.

Out of all the studies in this review that evaluated toxicity, 5 patients presented with grade 5 toxicity and 19 with grade 3 toxicity. The majority of grade 5 toxicities were related to hemoptysis, fistulas or excess dose to proximal bronchial tree and its vasculature.

\section{Quality of the studies}

The overall quality of the studies was measured with 
Table 2 Ongoing clinical trials found in clinicaltrial.org on Feb 2020 with the keywords "SBRT stage III NSCLC"

\begin{tabular}{|c|c|c|c|c|c|c|c|c|}
\hline & $\begin{array}{l}\text { Clinical trial } \\
\text { identifier }\end{array}$ & Interventions & Status & $\mathrm{N}$ & Phase & CRT Fr & SBRT Fr & Results \\
\hline \multirow[t]{5}{*}{$\begin{array}{l}\text { SBRT } \\
\text { and CRT } \\
\text { combinations }\end{array}$} & NCT03589547 & $\begin{array}{c}\text { SBRT- } \\
\text { durvalumab } \rightarrow \\
\text { CRT }\end{array}$ & Recruiting & 25 & II & $60 / 30$ & $20 / 2 \mathrm{Fr}$ & Not available \\
\hline & NCT02400424 & $\begin{array}{l}\mathrm{CRT} \rightarrow \mathrm{SBRT} \\
\text { peripheral }\end{array}$ & $\begin{array}{l}\text { Active, not } \\
\text { recruiting }\end{array}$ & 70 & II & 66/33 LN & 54/3 Fr T & Not available \\
\hline & $\begin{array}{c}\text { NCT01933568 } \\
\text { N12HYB }\end{array}$ & $\begin{array}{c}\text { CRT + SBRT for } \\
\text { peripheral } \mathrm{T}<5 \\
\mathrm{~cm}\end{array}$ & Completed & 15 & I & \multicolumn{2}{|c|}{$\begin{array}{l}\text { CRT to } \mathrm{LN} \text { and SBRT to PT } \\
\text { concurrent to cisplatin }\end{array}$} & Not available \\
\hline & NCT01657617 & $\mathrm{SBRT} \rightarrow \mathrm{CRT}$ & Completed & 35 & II & CRT & $\begin{array}{c}\text { 19.5/3 Fr CT; } \\
\text { 20/2 PT }\end{array}$ & $\begin{array}{c}2 \text { G5 hemoptysis; } 2 \\
\text { G3 pneumonitis }\end{array}$ \\
\hline & NCT02262325 & $\mathrm{SBRT} \rightarrow \mathrm{CRT}$ & Recruiting & 34 & II & $30 \mathrm{Fr}$ & $2 \mathrm{Fr}$ & Not available \\
\hline SBRT & NCT03727867 & $\begin{array}{c}\text { TKI + SBRT } \\
\text { (EGFR) }\end{array}$ & $\begin{array}{l}\text { Not yet } \\
\text { recruiting }\end{array}$ & 300 & III & NA & $\begin{array}{c}\text { 60/8 Fr CT; } \\
\text { 50/5 PT }\end{array}$ & Not available \\
\hline
\end{tabular}

CRT, conventional chemoradiation; SBRT, stereotactic body radiotherapy; Fr, fractionation in total Gy and number of fractions; LN, lymph nodes; T, tumor; NI, no information; PT, peripheral tumors; CT, central tumors; TKI, tyrosine kinase inhibitor; NA, not applicable.

the NIH tool that was more adequate for each design. Prospective studies were analyzed with the "before-after studies with no control group" (Figure 2) and retrospective studies were analyzed with the "Case Series Studies Tool" (Figure 3). Out of the retrospective studies selected, one study did not have the statistics clearly outlined, another study did not include grades on toxicity, and all 3 studies included heterogeneous population with different disease stages. Only one of the studies specified clearly the patient characteristics. The nature of SBRT treatment on the other hand, did not allow for double blinded design in the prospective studies and the scarce number of patients treated with SBRT does not permit to draw conclusions on the heterogeneous stage III NSCLC population.

\section{Future perspectives}

At present, SBRT administration in stage III is being studied in 7 different clinical trials (Table 2). One of them combines SBRT with TKI (NCT03727867). Six phase II studies are ongoing, of which one has already closed recruitment
(NCT01656460). One of these trials (NCT03589547) uses SBRT and Durvalumab as a neoadjuvant strategy before definitive chemoradiation.

\section{Conclusions}

Current evidence to administer SBRT in inoperable stage III locally advanced NSCLC is based on two phase I trials. As far as fractionation is concerned, authors establish that 2 fractions of 10 or 12 Gy each are safe after conventional chemoradiation and obtain a local control of around $78 \%$. Hence, increasing biological effective dose above 112.3 Gy seems to have a better local control compared to conventional radiation. Ongoing phase II and III clinical trials will determine the efficacy of this treatment approach and confirm the toxicity in comparison to the standard treatment.

\section{Acknowledgments}

Funding: None. 


\section{Footnote}

Provenance and Peer Review: This article was commissioned by the Guest Editor (Mariano Provencio) for the series "Multimodal management of locally advanced N2 nonsmall cell lung cancer" published in Translational Lung Cancer Research. The article has undergone external peer review.

Conflicts of Interest: All authors have completed the ICMJE uniform disclosure form (available at http://dx.doi. org/10.21037/tlcr-2020-nsclc-04). The series "Multimodal management of locally advanced N2 non-small cell lung cancer" was commissioned by the editorial office without any funding or sponsorship. The authors have no other conflicts of interest to declare.

Ethical Statement: The authors are accountable for all aspects of the work in ensuring that questions related to the accuracy or integrity of any part of the work are appropriately investigated and resolved.

Open Access Statement: This is an Open Access article distributed in accordance with the Creative Commons Attribution-NonCommercial-NoDerivs 4.0 International License (CC BY-NC-ND 4.0), which permits the noncommercial replication and distribution of the article with the strict proviso that no changes or edits are made and the original work is properly cited (including links to both the formal publication through the relevant DOI and the license). See: https://creativecommons.org/licenses/by-nc-nd/4.0/.

\section{References}

1. Cheema PK, Rothenstein J, Melosky B, et al. Perspectives on treatment advances for stage III locally advanced unresectable non-small-cell lung cancer. Curr Oncol 2019;26:37-42.

2. Postmus PE, Kerr KM, Oudkerk M, et al. Early and locally advanced non-small-cell lung cancer (NSCLC): ESMO Clinical Practice Guidelines for diagnosis, treatment and follow-up. Ann Oncol 2017;28:iv1-iv21.

3. Aupérin A, Le Péchoux C, Rolland E, et al. Meta-analysis of concomitant versus sequential radiochemotherapy in locally advanced non-small-cell lung cancer. J Clin Oncol 2010;28:2181-90.

4. Majem M, Juan O, Insa A, et al. SEOM clinical guidelines for the treatment of non-small cell lung cancer (2018).
Clin Transl Oncol 2019;21:3-17.

5. McGarry RC. Integrating stereotactic body radiation therapy in stage II/III non-small cell lung cancer: is local control important? Expert Rev Anticancer Ther 2014;14:1419-27.

6. Bradley JD, Paulus R, Komaki R, et al. Standard-dose versus high-dose conformal radiotherapy with concurrent and consolidation carboplatin plus paclitaxel with or without cetuximab for patients with stage IIIA or IIIB non-small-cell lung cancer (RTOG 0617): a randomised, two-by-two factorial phase 3 study. Lancet Oncol 2015;16:187-99.

7. Navarro-Martin A, Aso S, Cacicedo J, et al. Phase II Trial of SBRT for Stage I NSCLC: Survival, Local Control, and Lung Function at 36 Months. J Thorac Oncol 2016;11:1101-11.

8. Haasbeek CJA, Palma D, Visser O, et al. Early-stage lung cancer in elderly patients: A population-based study of changes in treatment patterns and survival in the Netherlands. Ann Oncol 2012;23:2743-7.

9. Timmerman R, McGarry R, Yiannoutsos C, et al. Excessive Toxicity When Treating Central Tumors in a Phase II Study of Stereotactic Body Radiation Therapy for Medically Inoperable Early-Stage Lung Cancer. J Clin Oncol 2006;24:4833-9.

10. Cong Y, Sun B, Wang J, et al. Outcomes and toxicity of stereotactic body radiation therapy for advanced stage ultra central non small cell lung cancer. Thorac Cancer 2019;10:1567-75.

11. Cong Y, Xuan L, Sun B, et al. Retrospective comparison of stereotactic body radiotherapy versus intensity-modulated radiotherapy for stage III ultra-central squamous nonsmall-cell lung cancer. Future Oncol 2019;15:1855-62.

12. Feddock J, Arnold SM, Shelton BJ, et al. Stereotactic Body Radiation Therapy Can Be Used Safely to Boost Residual Disease in Locally Advanced Non-Small Cell Lung Cancer: A Prospective Study. Int J Radiat Oncol Biol Phys 2013;85:1325-31.

13. Hepel JT, Leonard KL, Safran H, et al. Stereotactic Body Radiation Therapy Boost After Concurrent Chemoradiation for Locally Advanced Non-Small Cell Lung Cancer: A Phase 1 Dose Escalation Study. Int J Radiat Oncol Biol Phys 2016;96:1021-7.

14. Higgins KA, Pillai RN, Chen Z, et al. Concomitant Chemotherapy and Radiotherapy with SBRT Boost for Unresectable Stage III Non-Small Cell Lung Cancer: A Phase I Study. J Thorac Oncol 2017;12:1687-95.

15. Kalman NS, Weiss E, Walker PR, et al. Local 
Radiotherapy Intensification for Locally Advanced Nonsmall-cell Lung Cancer - A Call to Arms. Clin Lung Cancer 2018;19:17-26.

16. Kumar S, Feddock J, Li X, et al. Update of a Prospective Study of Stereotactic Body Radiation Therapy for PostChemoradiation Residual Disease in Stage II/III NonSmall Cell Lung Cancer. Int J Radiat Oncol Biol Phys 2017;99:652-9.

17. Peulen H, Franssen G, Belderbos J, et al. SBRT combined with concurrent chemoradiation in stage III NSCLC: Feasibility study of the phase I Hybrid trial. Radiother Oncol 2020;142:224-9.

18. Salazar OM, Sandhu TS, Lattin PB, et al. Once-Weekly, High-Dose Stereotactic Body Radiotherapy for Lung Cancer: 6-Year Analysis of 60 Early-Stage, 42 Locally Advanced, and 7 Metastatic Lung Cancers. Int J Radiat Oncol Biol Phys 2008;72:707-15.

19. Karam SD, Horne ZD, Hong RL, et al. Dose escalation with stereotactic body radiation therapy boost for locally advanced non small cell lung cancer. Radiat Oncol 2013;8:179.

20. Rodrigues G, Choy H, Bradley J, et al. Definitive radiation therapy in locally advanced non-small cell lung cancer: Executive summary of an American Society for Radiation Oncology (ASTRO) evidence-based clinical practice guideline. Pract Radiat Oncol 2015;5:141-8.

21. Chang JY, Li QQ, Xu QY, et al. Stereotactic Ablative Radiation Therapy for Centrally Located Early Stage or Isolated Parenchymal Recurrences of Non-Small Cell Lung Cancer: How to Fly in a "No Fly Zone." Int J Radiat Oncol Biol Phys 2014;88:1120-8.

22. Senthi S, Haasbeek CJA, Slotman BJ, et al. Outcomes of stereotactic ablative radiotherapy for central lung tumours: A systematic review. Radiother Oncol 2013;106:276-82.

23. Matsushita H, Jingu K, Umezawa R, et al.

Cite this article as: Alcibar OL, Nadal E, Romero Palomar I, Navarro-Martin A. Systematic review of stereotactic body radiotherapy in stage III non-small cell lung cancer. Transl Lung Cancer Res 2021;10(1):529-538. doi: 10.21037/tlcr-2020nsclc-04
Stereotactic Radiotherapy for Oligometastases in Lymph Nodes-A Review. Technol Cancer Res Treat 2018;17:1533033818803597.

24. Sollini M, Cozzi L, Antunovic L, et al. PET Radiomics in NSCLC: state of the art and a proposal for harmonization of methodology. Sci Rep 2017;7:358.

25. Lopez Guerra JL, Gladish G, Komaki R, et al. Large decreases in standardized uptake values after definitive radiation are associated with better survival of patients with locally advanced non-small cell lung cancer. J Nucl Med 2012;53:225-33.

26. Schaue D, Ratikan JA, Iwamoto KS, et al. Maximizing Tumor Immunity With Fractionated Radiation. Int J Radiat Oncol Biol Phys 2012;83:1306-10.

27. Vanpouille-Box C, Alard A, Aryankalayil MJ, et al. DNA exonuclease Trex1 regulates radiotherapy-induced tumour immunogenicity. Nat Commun 2017;8:15618.

28. Deng L, Liang H, Fu S, et al. From DNA Damage to Nucleic Acid Sensing: A Strategy to Enhance Radiation Therapy. Clin Cancer Res 2016;22:20-5.

29. Antonia SJ, Villegas A, Daniel D et al. Overall survival with durvalumab after chemoradiotherapy in stage III NSCLC. N Engl J Med 2018;379:2342-50.

30. Luke JJ, Lemons JM, Karrison TG, et al. Safety and Clinical Activity of Pembrolizumab and Multisite Stereotactic Body Radiotherapy in Patients With Advanced Solid Tumors. J Clin Oncol 2018;36:1611-8.

31. Bezjak A, Paulus R, Gaspar LE, et al. Safety and Efficacy of a Five-Fraction Stereotactic Body Radiotherapy Schedule for Centrally Located Non-Small-Cell Lung Cancer: NRG Oncology/RTOG 0813 Trial. J Clin Oncol 2019;37:1316-25.

32. Normolle D, Lawrence T. Designing dose-escalation trials with late-onset toxicities using the time-to-event continual reassessment method. J Clin Oncol 2006;24:4426-33. 